\title{
ETNOCONHECIMENTO DE PESCADORES ARTESANAIS SOBRE A ICTIOFAUNA DO RIO JIQUIRIÇÁ, BAHIA
}

\section{ETHNO-KNOWLEDGE OF ARTISANAL FISHERS ON THE ICHTHYOFAUNA OF THE JIQUIRIÇÁ RIVER, BAHIA}

Tiago Abreu da SILVA ${ }^{*}$; Wanderley Diaciso dos Santos OLIVEIRA ${ }^{2}$; Francisco Alexandre Costa SAMPAIO ${ }^{1}$

${ }^{1}$ Instituto Federal de Educação, Ciência e Tecnologia Baiano, Santa Inês, Bahia, Brasil. ${ }^{2}$ Universidade Federal do Recôncavo da Bahia, Cruz das Almas, Bahia, Brasil.

*tiagoabreu5389@gmail.com

Submitted: 12/11/2020; Accepted: 04/02/2021; Published: 12/03/2021

\section{RESUMO}

Uma das práticas culturais que se mantém ativa ao longo dos anos é a pesca desenvolvida e aperfeiçoada, de forma artesanal, por observações e/ou conhecimento hereditário. Conhecer as experiências destes pescadores configura-se em uma alternativa para entender a composição da ictiofauna de uma determinada localidade. O objetivo deste estudo foi identificar o conhecimento dos pescadores sobre as espécies de peixes do rio Jiquiriçá e sua interação com o ambiente, norteado pela hipótese de que seus conhecimentos são originários de sua relação com o meio. Foram realizadas entrevistas com 14 pescadores e 9 pescadoras do município de Ubaíra, BA, utilizando-se a técnica "Snowball". As entrevistas foram gravadas em áudio e posteriormente transcritas na íntegra. Os resultados apontaram para o etnoconhecimento dos entrevistados em relação aos aspectos da biologia dos peixes, tais como hábitos alimentares e reprodução. Percepções sobre estratégias de pesca e espécies introduzidas no rio nos últimos 20 anos, também foram registradas. Devido às condições desfavoráveis ao exercício da pesca (assoreamento, poluição, contaminação por esquistossomose), a maioria dos entrevistados abandonou esta atividade no rio Jiquiriçá. Porém, através deles foi possível perceber a necessidade de recuperação do rio para que a atividade da pesca artesanal seja sócio e ambientalmente viável, principalmente devido à contaminação.

PALAVRAS-CHAVE: Biodiversidade, Espécies exóticas, Etnoictiologia, Pesca artesanal, Peixes.

\begin{abstract}
Artisanal fisher communities are influenced by the environment and their daily contact with natural resources generates traditional knowledge about local ichthyofauna. The aim of this study was to evaluate fisher perceptions of the fish species of the Jiquiriçá River and assess their interactions with the environment, guided by the hypothesis that the artisanal fishers have vast knowledge originating from their relationship with the environment. Interviews were conducted with 14 male and nine female fishers from the municipality of Ubaíra, state of Bahia, Brazil, using the snowball method. The interviews were audio recorded and fully transcribed. The data indicated the interviewees' ethno-knowledge regarding aspects of fish biology, such as feeding habits and reproduction. Perceptions about fishing methods and species introduced in the last 20 years were also recorded. Due to unfavorable conditions for fishing (silting, pollution, schistosomiasis contamination), most of the interviewees had abandoned fishing in the Jiquiriçá River. Nonetheless, the interviewees expressed an urgent need to develop ways of recovering and conserving the river
\end{abstract}


SILVA, T.A.; OLIVEIRA, W.D.S.; SAMPAIO, F.A.C. Etnoconhecimento de pescadores artesanais sobre a ictiofauna do Rio Jiquiriçá, Bahia. Ethnoscientia v.6 n. 1, 2021. DOI: 10.22276/ethnoscientia.v6i1.375

and to strengthen subsistence activities, involving different social actors, with the aim of reducing the impacts of anthropogenic actions.

KEYWORDS: Biodiversity, Alien species, Ethnoichthyology, Artisanal fishing, Fishes.

\section{INTRODUÇÃO}

O homem em busca de compreender sua própria existência e o mundo que o rodeia, desenvolve hábitos, regras e conceitos que os aproxima ao convívio com o meio natural e o orienta no processo de reconhecimento como parte deste. Esta técnica que é espontânea, cumulativa e fragmentada contribui com a formação do conhecimento tradicional (ROZARIO et al., 2018).

Tal conhecimento é uma ciência distinta, específica dos diversos grupos populacionais, formada a partir de vivências experimentadas por homens e mulheres de delimitada área geográfica que inter-relacionam suas experiências com o mundo, práticas, significados e valores, considerando o contexto natural e cultural de onde vivem (TOLEDO e BARRERA-BASSOLS, 2010; SILVA e BRAGA, 2017).

Este saber sofisticado e detalhado, faz do etnoconhecimento uma das principais formas de produzir ciência sobre as especificidades de um local (MOURA e MARQUES, 2008; ROZARIO et al., 2018). Quando a ciência de "folk", ou seja, a cognição de determinado grupo populacional, passada geração após geração, está relacionada à interação peixe/pescador, esta é definida como etnoictiologia (MARQUES, 1991). Desta forma fica evidente o conceito de que etnoictiologia é a ciência ictiológica nativa (MARQUES, 2012), ou em outros termos, é o estudo do saber e conviver desenvolvidos por determinada comunidade de pescadores acerca dos peixes e seu ambiente (MOURÃO e NORDI, 2002).

Milhões de pessoas em todo o mundo utilizam a pesca como fonte de renda e subsistência. Dados da Fundação das Nações Unidas afirmam que até o ano de 2016 existiam 40,3 milhões de pescadores identificados em seus diversos países (FAO, 2018). Porém, mesmo com a expansão da tecnologia, são encontradas comunidades de pescadores sem registros oficiais, atuando de modo artesanal e se beneficiando dos peixes não apenas como fonte de renda, mas principalmente para alimentação e sustento da família (BENTO e BEMVENUTI, 2008).

Para Santos et al. (2018) a diferença entre pesca artesanal e industrial está nas técnicas, espécie alvo e quantidade de captura. Conforme estes autores, pescadores 
SILVA, T.A.; OLIVEIRA, W.D.S.; SAMPAIO, F.A.C. Etnoconhecimento de pescadores artesanais sobre a ictiofauna do Rio Jiquiriçá, Bahia. Ethnoscientia v.6 n. 1, 2021. DOI: 10.22276/ethnoscientia.v6i1.375

artesanais, no geral trabalham de forma individual ou em grupos familiares utilizando técnicas simples de pesca.

Comunidades de pescadores tradicionais possuem o modo de vida influenciado pelo convívio com o ambiente natural. O contato diário deste público com o meio e os recursos naturais gera um conhecimento local tradicional sobre as espécies, principalmente na conservação e uso sustentável da ictiofauna local (SANTOS et al., 2018; ZEINEDDINE et al., 2018).

A interação peixe/pescador que acontece em comunidades tradicionais vai além da rotina da atividade pesqueira, pois quando verbalizada reflete símbolos, crenças, costumes e percepções que caracterizam grupos populacionais diversos (MARQUES, 2012). Assim, as pesquisas foram norteadas pela hipótese de que os pescadores artesanais do município de Ubaíra - Bahia, que desenvolvem as atividades de pesca no rio Jiquiriçá, possuem um conhecimento etnológico formado a partir de sua relação com os peixes e com o meio ambiente em que estão inseridos. Desta forma, este trabalho teve por objetivo registrar o etnoconhecimento dos pescadores e pescadoras, por meio dos aspectos cognitivos e comportamentais encontrados na interação deste grupo populacional com os peixes, com o ambiente em que vivem e desenvolvem suas atividades de subsistência.

\section{MATERIAL E MÉTODO}

\section{1 Área de estudo}

Este estudo foi realizado na cidade de Ubaíra, localizada no território de identidade do Vale do Jiquiriçá, Estado da Bahia, especificamente nas comunidades rurais de Engenheiro Franca, Jenipapo, Araci, Lagoa das Flechas e Barra da Estopa assim como na zona urbana (Figura 1). O município de Ubaíra, em 2018, tinha uma população estimada de 19.914 habitantes e possui área de 659,14 km² (SEI, 2019; IBGE, 2019). 


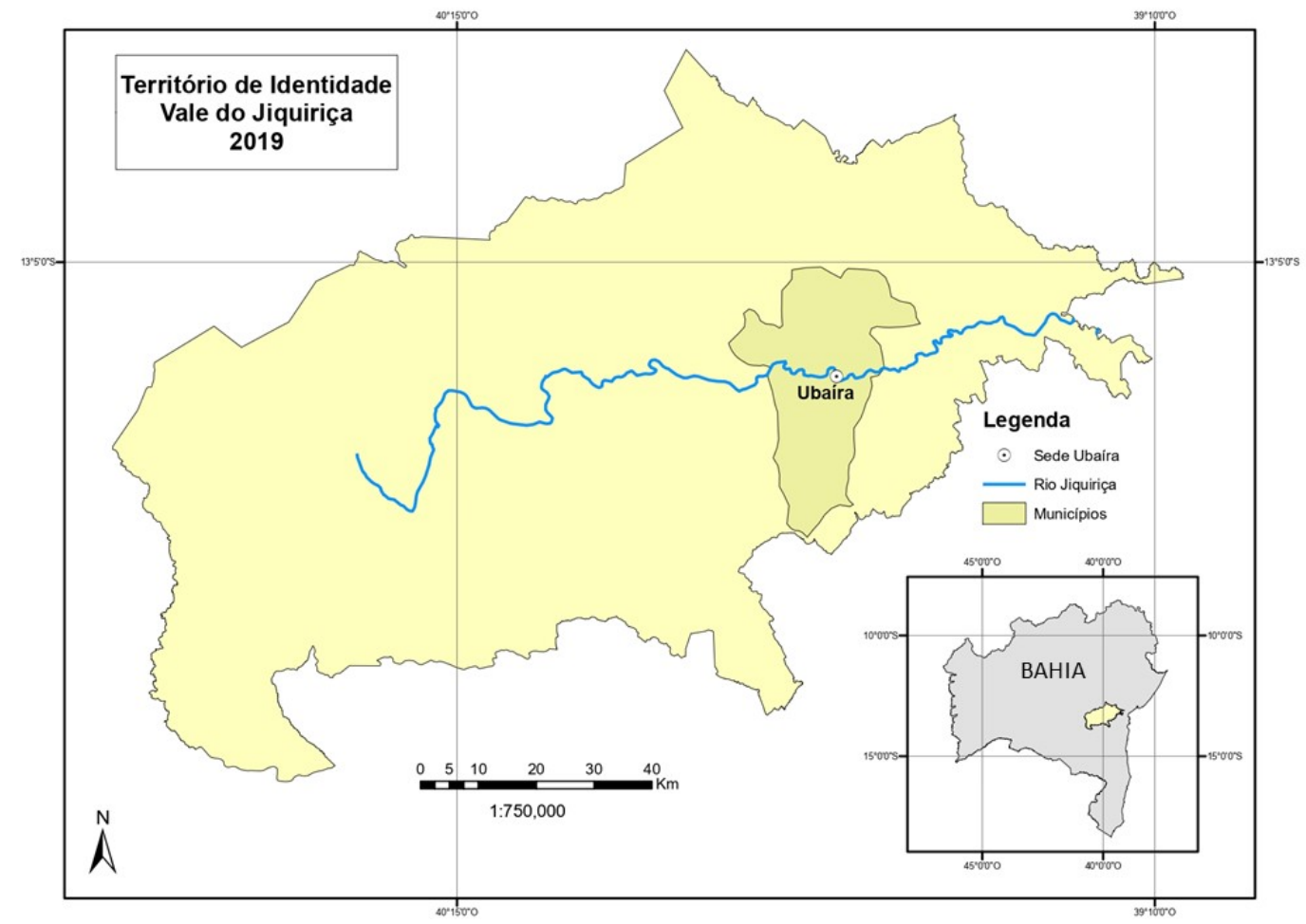

Figura 1: Localização da área de estudo no município de Ubaíra, bacia do rio Jiquiriçá, Bahia (Fonte: Elaborada pelos autores).

O rio Jiquiriçá, com $275 \mathrm{~km}$ de extensão, corta todo o território de identidade que leva seu nome, constituindo-se como relevante elo cultural e de desenvolvimento econômico para a região, principalmente a pesca de subsistência. A sua história com a população local vem desde o início da formação dos povoados pelos tropeiros, pois foram às suas margens que se instituíram o princípio dos centros urbanos atuais. Aqueles que migraram para esta redondeza, atraídos pelas riquezas naturais e fertilidade do solo local, fizeram do rio Jiquiriçá um intenso elemento de referência (BATISTA, 2003).

\subsection{Coleta de dados}

No período de setembro e outubro de 2020 foram realizadas entrevistas semiestruturadas, com 23 pescadores e pescadoras, nas áreas rural e urbana do município, considerados os mais experientes na atividade pesqueira, segundo seus pares, todos com mais de 18 anos de idade. Para a escolha dos participantes foi utilizada a técnica "Snowball" (bola de neve) ou "chain referral sampling" (amostra de referência em cadeia), a qual gera uma amostragem a partir de indicações entre pessoas que comungam 
SILVA, T.A.; OLIVEIRA, W.D.S.; SAMPAIO, F.A.C. Etnoconhecimento de pescadores artesanais sobre a ictiofauna do Rio Jiquiriçá, Bahia. Ethnoscientia v.6 n. 1, 2021. DOI: 10.22276/ethnoscientia.v6i1.375

características de interesse da pesquisa (BIERNACKI e WALDORF, 1981). Neste sentido, os pescadores entrevistados informavam outros especialistas nativos (MARQUES, 2001).

As entrevistas tiveram tempo de duração livre. Foram consideradas aquelas com o mínimo de 30 minutos, sendo 52 a de maior duração. Foi realizada apenas uma com cada pescador/pescadora em local escolhido pelo próprio participante (bar, casa, quintal ou jardim). Tendo em vista a necessidade do distanciamento social devido a pandemia da Covid-19, optou-se, ainda assim, por manter as entrevistas de forma presencial, obedecendo rigorosamente a todas as orientações dos órgãos de saúde.

Dos 23 entrevistados, 14 eram homens e 9 mulheres, com idade média de 61 anos. Quanto ao tempo de atuação na pesca, os entrevistados tinham de 4 a 50 anos de experiência pesqueira, representando um tempo médio de 13 anos.

As perguntas e respostas foram gravadas em áudio, sob autorização de cada pessoa entrevistada por meio de termo de consentimento livre e esclarecido. Este estudo obteve autorização pelo comitê de ética em pesquisa da Universidade Estadual do Sudoeste da Bahia - Campus Jequié, sob o parecer de número 4.130.426.

Posteriormente as informações coletadas foram transcritas e digitalizadas, mantendo-se as palavras e expressões originais dos entrevistados visando garantir a fidelidade dos dados. Em seguida houve a tabulação e análise quali-quantitativa do material, bem como a verificação de anotações feitas em diário de campo. Os resultados foram discutidos utilizando a técnica de cognição comparada (MARQUES, 2001), além da discriminação da categoria trófica, distribuição espacial dos peixes, indicação dos petrechos de pesca e o etnoconhecimento dos pescadores acerca das espécies não-nativas.

Alguns pescadores forneceram exemplares de peixes capturados por eles no rio Jiquiriçá, os quais foram utilizados para a identificação taxonômica das espécies, por meio de bibliografia especializada (GRAÇA E PAVANELLI, 2007; BURGER et al., 2011) e em seguida, fixados em formaldeído e conservados em solução de álcool a 70\%.

Para melhor direcionamento das prováveis espécies, que apesar de serem citadas pelos entrevistados não estavam dentre os exemplares fornecidos, houve a utilização da técnica estímulo visual (MEDEIROS et al, 2010), através da apresentação de imagens fotográficas de variedades de peixes que possuem características concordantes com aquelas fornecidas durante as entrevistas. Os questionários e os exemplares de peixes constituem material testemunho e foram depositados no Laboratório de Zoologia do Instituto Federal de Educação Ciência e Tecnologia Baiano, Campus Santa Inês. 
SILVA, T.A.; OLIVEIRA, W.D.S.; SAMPAIO, F.A.C. Etnoconhecimento de pescadores artesanais sobre a ictiofauna do Rio Jiquiriçá, Bahia. Ethnoscientia v.6 n. 1, 2021. DOI: 10.22276/ethnoscientia.v6i1.375

\section{RESULTADOS E DISCUSSÃO}

Por meio das entrevistas obteve-se dos pescadores e pescadoras a indicação de 19 variedades de peixes que afirmaram existir ou que já existiram no rio Jiquiriçá (Tabela 1). Algumas dessas foram coletadas, registrando a ocorrência delas no rio tanto pela captura dos pescadores quanto por outros estudos (BURGER et al., 2011). Entretanto, existem peixes que, apesar de indicados pelos entrevistados, não foram registrados por Burger et al. (2011) e nem capturadas no período de execução deste trabalho, o que pode indicar que estas vem desaparecendo ou tenham sido extintas localmente, a exemplo da "moreia", "robalo" e "piabanha", embora citadas por 39\%, 22\% e 26\%, respectivamente, dos entrevistados de diferentes localidades (Tabela 1).

Tabela 1. Peixes do rio Jiquiriçá e percentual (\%) indicados por pescadores artesanais de Ubaíra, Bahia e seus respectivos nomes científicos.

\begin{tabular}{ll}
\hline Acará, Beré (52) & Geophagus brasiliensis (Quoy \&Gaimard, 1824) \\
Acari, Chupa pedra, Cascudo (70) & Hypostomus sp \\
Bagre (4) & Pimelodus sp \\
Bobó, Pari-vivo, Durin (35) & Poecilia reticulata (Peters, 1859) \\
Camboatá, Cambuti (9) & Callichthys sp \\
Carpa (13) & Cyprinus sp \\
Curimbatá, Curumatá, Curimatã (26) & Prochilodus lineatus (Valenciennes, 1836) \\
Jundiá (83) & Rhamdia quelen (Quoy \&Gaimard, 1824) \\
Moreira, Moreia, Lisa (39) & Não identificado \\
Pescada branca (9) & Plagioscion sp* \\
Piaba do rabo vermelho (74) & Astyanax fasciatus (Cuvier, 1819) \\
Piaba do rabo amarelo (74) & Astyanax gr bimaculatus (Linaeus, 1758) \\
Piabanha (26) & Brycon sp* \\
Piau (96) & Leporinus paranensis (Garavello e Britski, 1987) \\
Robalo (22) & Centropomus sp* \\
Tambaqui (9) & Colossoma sp \\
Tilápia, Tilápi (91) & Oreochromis niloticus (Linnaeus, 1758) \\
Traíra (91) & Hoplerythrinus unitaeniatus (Agassiz, 1829) \\
Tucunaré (9) & Cichla sp \\
\hline
\end{tabular}

\footnotetext{
* Pista taxonômica.
}

Durante as entrevistas, foi possível perceber que os peixes mais citados foram aqueles que a comunidade utilizava para alimentação da própria família. "Acari não tem espinha nenhuma dentro, uma muquequinha dele é muntcho gostosa, a gente comia direto" 
SILVA, T.A.; OLIVEIRA, W.D.S.; SAMPAIO, F.A.C. Etnoconhecimento de pescadores artesanais sobre a ictiofauna do Rio Jiquiriçá, Bahia. Ethnoscientia v.6 n. 1, 2021. DOI: 10.22276/ethnoscientia.v6i1.375

(E.13). "No outro dia, depois da pescaria, juntava a gente tudo pra comer piaba frita na farinha" (E.22). "A traíra tem a carne boa, mas tem muita espinha, mas a gente comia" (E.14). "Depois que apareceu a tilápia que foi bom, a carne é gostosa, tinha tanta que dava pra vender e comer" (E.15).

Mediante as características morfológicas descritas pelos entrevistados e afirmação através do estímulo visual, o peixe conhecido pelos pescadores como "moreia" provavelmente seja identificado como Awaous tajasica, da família Gobiidae, que em outras regiões do Brasil também recebe esta denominação popular (VIEIRA et al., 2014). Esta espécie de influência marinha, ocorre também em ambientes aquáticos de fundos arenosos, em geral, em trechos baixos do curso dos rios ou próximos da foz (SARMENTO-SOARES et al., 2009; VIEIRA et al., 2014). Neste estudo, a ocorrência destes indivíduos foi indicada por pescadores na área analisada, distante aproximadamente $90 \mathrm{~km}$ da foz. Já o peixe denominado por "robalo" ocorre também em regiões de rios distantes da foz e assim como a moreia, teve seu registro confirmado pelos entrevistados nesta localidade. Este pertence à família Centropomidae, com várias espécies do gênero Centropomus, conhecidas popularmente por robalos (FROESE e PAULY, 2019) que são bem visadas por pescadores (VIEIRA et al., 2014) e neste estudo, os entrevistados afirmaram que o peixe tem se tornado cada vez mais raro. É possível também que estas indicações, devido à variação dos nomes populares, sejam pertencentes a outros táxons, que por não dispor de exemplares, não foi possível a confirmação.

Faz-se necessário salientar, mesmo que não possa afirmar precisamente a quais táxons se referem, os peixes indicados têm fundamental importância para o registro deles no rio, dado ao contexto temporal. Assim como a moreia e o robalo, por exemplo, outros peixes que compõem a ictiofauna da área analisada podem, no futuro, não ser conhecidos pelas próximas gerações, perdendo-se este vínculo cultural e ambiental, dado ao seu relevante valor biológico.

\subsection{Etnoconhecimento dos pescadores artesanais sobre a biologia dos peixes}

O etnoconhecimento dos pescadores apontou informações acerca da biologia dos peixes, a exemplo da reprodução e outros hábitos. Neste sentido ganha destaque a cognição sobre a escolha do local para reprodução, construção de ninhos, a territorialidade dos machos, fecundação externa e cuidado com a prole, conforme registrado no Quadro 1. 
SILVA, T.A.; OLIVEIRA, W.D.S.; SAMPAIO, F.A.C. Etnoconhecimento de pescadores artesanais sobre a ictiofauna do Rio Jiquiriçá, Bahia. Ethnoscientia v.6 n. 1, 2021. DOI: 10.22276/ethnoscientia.v6i1.375

Embora tenham sido indicadas 19 variedades de peixes, nem todas tiveram informações fornecidas pelos pescadores que pudessem compor os quadros a seguir.

Quadro 1. Cognição comparada sobre a reprodução e outros hábitos dos peixes por pescadores do rio Jiquiriçá, Bahia.

\begin{tabular}{|c|c|c|}
\hline $\begin{array}{c}\text { Nome do } \\
\text { peixe }\end{array}$ & Citação do pescador & Citação da literatura \\
\hline \multirow[b]{2}{*}{ 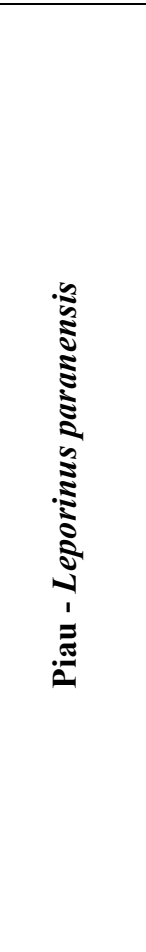 } & $\begin{array}{l}\text { “(...) porque o piau na verdade que sobe, ele sobe } \\
\text { bastante o rio até quando eles poderem, (...), eles } \\
\text { sobem a corredeira o máximo que eles poder, } \\
\text { chegam dentro da vegetação aquática, daquela } \\
\text { vegetação aquática ali e ali eles começam a } \\
\text { desovar.” E-3 }\end{array}$ & $\begin{array}{l}\text { Leporinus sp - de maneira geral são } \\
\text { espécies com reprodução anual, que } \\
\text { realizam migrações curtas ou longas até } \\
\text { as regiões de cabeceira" } \\
\text { (VASCONCELLOS, 2007). }\end{array}$ \\
\hline & $\begin{array}{l}\text { “(...) aquele momento ali que ele começa a } \\
\text { desovar, você percebe a água esbranquiçada, } \\
\text { como se fosse leite, tivesse derramado leite, } \\
\text { aquilo ali é o macho liberando esperma, } \\
\text { espermatozoide e nesse momento, as fêmeas } \\
\text { liberam as ovas (...).” E-3 } \\
\text { "Na época da desova, você pega, ele solta um } \\
\text { leite pelo canalzinho dele aí você distingue macho } \\
\text { e fêmea.” E-22 }\end{array}$ & $\begin{array}{l}\text { Conforme Silva Filho et al. (2012), os } \\
\text { testículos dos machos de Leporinus sp, } \\
\text { ao atingirem estado de maturação } \\
\text { gonadal e ao receberem leve pressão o } \\
\text { líquido espermático flui. }\end{array}$ \\
\hline \multirow[b]{2}{*}{ 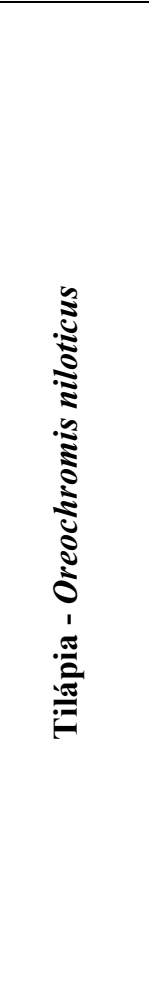 } & $\begin{array}{l}\text { "(...) pra se reproduzir ela procura mais as } \\
\text { beiradas porque ela precisa fazer o chamado, a } \\
\text { gente chama ninho, é a barroca." E-3 }\end{array}$ & $\begin{array}{l}\text { Os cardumes movem-se para zonas } \\
\text { costeiras litorais com águas rasas, onde } \\
\text { os machos competem entre si para a } \\
\text { aquisição e manutenção de arenas } \\
\text { reprodutivas (SILVA, 2015). }\end{array}$ \\
\hline & $\begin{array}{l}\text { “(...) ela é um peixe territorialista também, onde } \\
\text { ela tem aquela barroca ali ela tem um raio que ela } \\
\text { não deixa nenhum se aproximar.” E-3 }\end{array}$ & $\begin{array}{l}\text { O sucesso de reprodução é fortemente } \\
\text { direcionado para machos dominantes } \\
\text { nos grupos estabelecidos, conjuntamente } \\
\text { com a capacidade de um macho } \\
\text { conseguir manter as arenas dentro da sua } \\
\text { área de territorialidade (SILVA, 2015). } \\
\text { O estabelecimento de territórios pelos } \\
\text { machos inicia com a construção de um } \\
\text { ninho de desova (...). A construção do } \\
\text { ninho começa com a "escavação" de } \\
\text { uma depressão rasa e estreita no }\end{array}$ \\
\hline
\end{tabular}


SILVA, T.A.; OLIVEIRA, W.D.S.; SAMPAIO, F.A.C. Etnoconhecimento de pescadores artesanais sobre a ictiofauna do Rio Jiquiriçá, Bahia. Ethnoscientia v.6 n. 1, 2021. DOI: 10.22276/ethnoscientia.v6i1.375

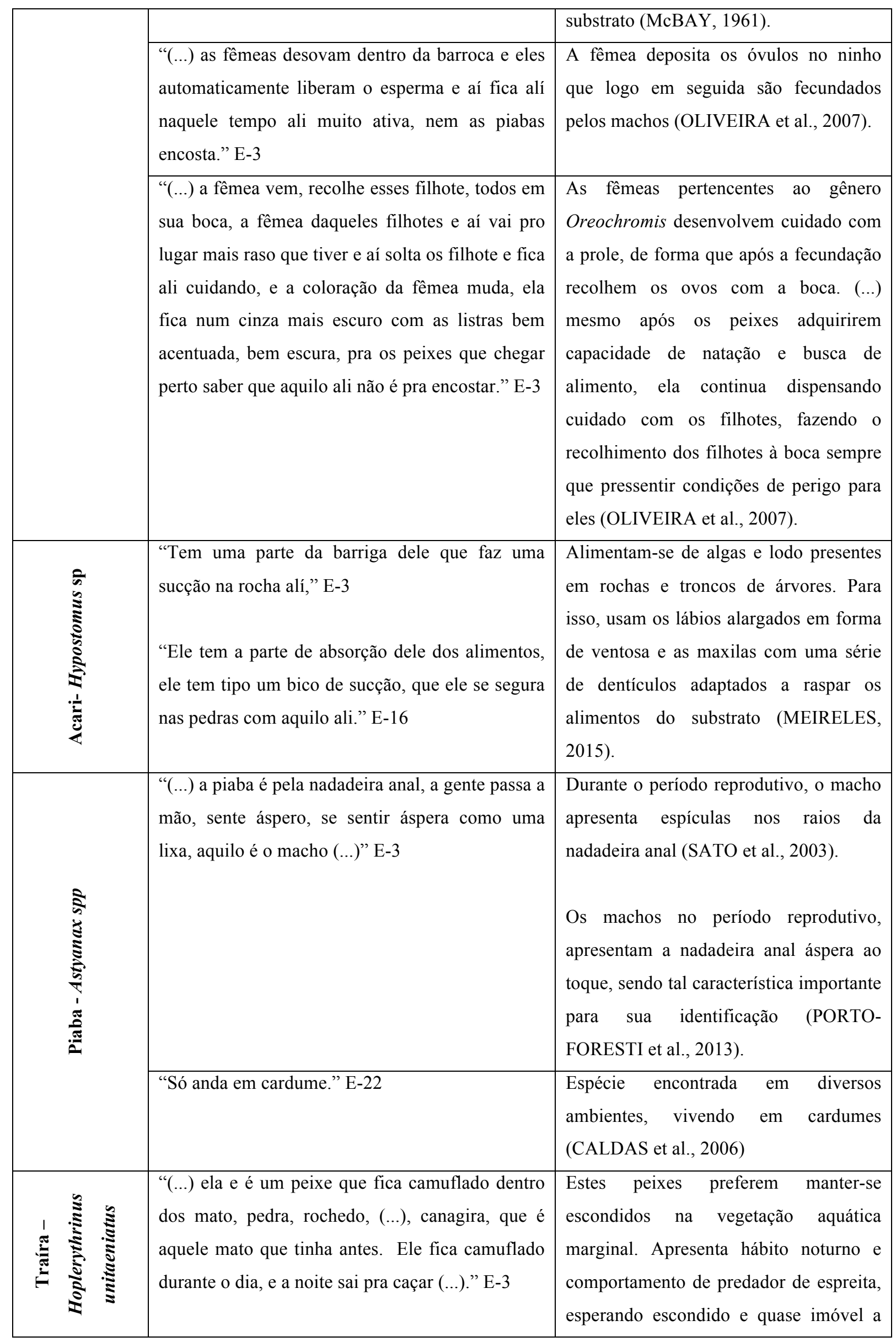




\begin{tabular}{|c|c|c|c|}
\hline & & & $\begin{array}{l}\text { aproximação de sua presa } \\
\text { (SANT'ANNA, 2006). } \\
\text { Possuem hábitos noturnos ou } \\
\text { crepusculares (LORO, 2013). }\end{array}$ \\
\hline & & $\begin{array}{l}\text { "A traíra não desaparece nunca, ela consegue } \\
\text { sobreviver na lama, os outros peixes não } \\
\text { conseguem, ela consegue viver na poluição, os } \\
\text { outro peixe não conseguem." E-18 }\end{array}$ & $\begin{array}{l}\text { Tem um poder extraordinário de } \\
\text { adaptação, sendo capaz de resistir às } \\
\text { condições mais adversas. Mergulham na } \\
\text { lama, resistindo até quando esta última } \\
\text { começa a endurecer (SANT'ANNA, } \\
\text { 2006). }\end{array}$ \\
\hline 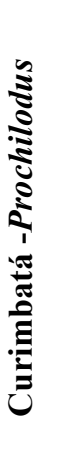 & 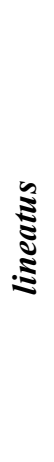 & $\begin{array}{l}\text { "Ele é um peixe de fácil reprodução, devido ele } \\
\text { praticar a piracema. Choveu, o rio encheu um } \\
\text { pouquinho, ele tá subindo rio acima pra praticar a } \\
\text { piracema." E-3 }\end{array}$ & $\begin{array}{l}\text { Os curimatãs realizam migrações com } \\
\text { fins reprodutivos, que estão } \\
\text { sincronizadas com as flutuações do nível } \\
\text { da água (FONSECA et al., 2013). } \\
\text { Realiza migrações reprodutivas em } \\
\text { grandes cardumes (CALDAS et al., } \\
\text { 2006). }\end{array}$ \\
\hline
\end{tabular}

Em pesquisa realizada com pescadores artesanais de três cidades do Vale do Ribeira, Ramires et al., (2007), também constataram o conhecimento detalhado destes atores sobre os aspectos da reprodução e outros comportamentos de peixes, os quais são confirmados através da literatura e evidenciam a importância do saber etnobiológico. Neste estudo o etnoconhecimento relacionado a comportamentos reprodutivos dos peixes sobrepõe-se em conformidade às evidências ictiológicas atuais, corroboradas pela literatura científica. No relato do pescador E-3, descrito no Quadro 1, sobre as características da piaba (Astyanax spp), este revelou a eficiente codificação corporal dos indivíduos. Além disso as observações sobre a liberação do óvulo e do gameta masculino na água da tilápia (Oreochromis niloticus) e do piau (Leporinus paranensis) como características reprodutivas de determinadas espécies de peixes coadunam com os registros encontrados na literatura.

As informações coletadas permitiram identificar o período aproximado do surgimento da tilápia no trecho estudado do rio Jiquiriçá. As declarações apontam que em meados da década de 1980 foram vistos os primeiros indivíduos desta espécie na região. Tal dado encontra consistência quando se obtém na literatura registros históricos da aquicultura brasileira que dão indícios comprobatórios dos relatos dos pescadores. Tais registros indicam que a partir das décadas de 1960 e 1970, um modelo popular de criação de peixes 
SILVA, T.A.; OLIVEIRA, W.D.S.; SAMPAIO, F.A.C. Etnoconhecimento de pescadores artesanais sobre a ictiofauna do Rio Jiquiriçá, Bahia. Ethnoscientia v.6 n. 1, 2021. DOI: 10.22276/ethnoscientia.v6i1.375

foi adotado para pequenos produtores, implantado com o objetivo de complementar a renda familiar (FARIA et al., 2014). Em 1971, o Departamento Nacional de Obras Contra as Secas (DNOCS) introduziu os primeiros espécimes de Oreochromis niloticus a fim de gerar alevinos para o repovoamento de reservatórios públicos da região Nordeste e avanço do cultivo (SCHULTER e VIEIRA FILHO, 2017). Mas, foi na década de 1980, que grandes quantidades de alevinos foram produzidas para repovoamentos e venda a produtores rurais, proporcionando uma rápida distribuição da espécie e sua introdução em diversos corpos hídricos e propriedades nas regiões Nordeste e Sudeste do Brasil (KUBITZA, 2003).

A confirmação dos relatos obtidos com registros da literatura reafirma que as observações realizadas por pescadores artesanais, durante suas vivências e interações com o meio, consolidam conhecimentos ricos em detalhes que caracterizam o ecossistema local. Trabalhos realizados por Marques (2001) em Marituba no baixo São Francisco alagoano e Thé et al., (2003) no alto-médio São Francisco, por exemplo também compararam informações fornecidas por pescadores com as da literatura na área e confirmaram a contribuição do conhecimento etnológico para a ciência.

\subsection{Etnoconhecimento dos pescadores artesanais sobre a alimentação dos peixes}

O conhecimento e a experiência como pescador artesanal leva ao desenvolvimento de estratégias de pesca e o uso de petrechos de maior eficiência pesqueira. Desta experiência surge o conhecimento adquirido sobre alimentação dos peixes, registrado no Quadro 2. Assim, conhecer a dieta dos peixes auxilia na compreensão do ecossistema local, mais especificamente na relação entre a ictiofauna e os diversos componentes presentes no ambiente aquático (POMPEU e GODINHO, 2003).

Quadro 2. Percepção comparada sobre a dieta dos peixes emitida por pescadores do rio Jiquiriçá, Bahia.

\begin{tabular}{|l|l|l|}
\hline Nome do peixe & Citação dos pescadores & $\begin{array}{l}\text { Categoria trófica } \\
\text { (ZAVALA- } \\
\text { CAMIN, 1996) }\end{array}$ \\
\hline $\begin{array}{l}\text { Acará } \\
\text { (Geophagus brasiliensis) }\end{array}$ & “(..) se alimenta também de minhoca (...)" E-3 & Onívoro \\
\hline $\begin{array}{l}\text { Acari } \\
\text { (Hypostomus sp.) }\end{array}$ & "Re alimenta do limo (algas) da rocha." E-3 & Herbívoro \\
\hline
\end{tabular}


SILVA, T.A.; OLIVEIRA, W.D.S.; SAMPAIO, F.A.C. Etnoconhecimento de pescadores artesanais sobre a ictiofauna do Rio Jiquiriçá, Bahia. Ethnoscientia v.6 n. 1, 2021. DOI: 10.22276/ethnoscientia.v6i1.375

\begin{tabular}{|c|c|c|}
\hline & "Só se alimentava de limo (algas)." E-22 & \\
\hline $\begin{array}{l}\text { Bobó } \\
\text { (Poecilia reticulata) }\end{array}$ & $\begin{array}{l}\text { "Se alimenta de alga, dessas particulazinha que } \\
\text { fica na água." E-3 } \\
\text { "Se alimentava de inseto, farinha, raízes, alevinos } \\
\text { de outros peixes, pedaço de carne." E- } 22\end{array}$ & Onívoro \\
\hline $\begin{array}{l}\text { Cambotá, Cambuti } \\
\text { (Callichthys sp.) }\end{array}$ & $\begin{array}{l}\text { "É limo (algas) também e lama. O cambuti } \\
\text { também é predador, ele pega outros peixes } \\
\text { também." E-4 } \\
\text { "Cambotá come até carniça." E-10 }\end{array}$ & Onívoro \\
\hline $\begin{array}{l}\text { Jundiá } \\
\text { (Rhamdia quelen) }\end{array}$ & $\begin{array}{l}\text { “(...) ele é um peixe que come de tudo, inclusive } \\
\text { peixe morto que tiver na água (...)" E-3 } \\
\text { "Ele come minhoca e outros peixe." E-23 }\end{array}$ & Onívoro \\
\hline $\begin{array}{l}\text { Piaba } \\
\text { (Astyanax sp.) }\end{array}$ & $\begin{array}{l}\text { "Ela se alimenta de tudo o que aparece na água, } \\
\text { principalmente inseto quando cai, (...), ela se } \\
\text { alimentava de esgoto também, (...), as ovas de } \\
\text { outros peixe (...)." E-3 } \\
\text { "A piaba geralmente é frutas, resto de alimentos." } \\
\text { E-6 }\end{array}$ & Onívoro \\
\hline $\begin{array}{l}\text { Piabanha } \\
\text { (Brycon sp.) }\end{array}$ & $\begin{array}{l}\text { “(..) limo (algas), essas coisa, inseto que cai na } \\
\text { água (...)” E-4 }\end{array}$ & Onívoro \\
\hline $\begin{array}{l}\text { Piau } \\
\text { (Leporinus paranensis) }\end{array}$ & $\begin{array}{l}\text { “Agora a alimentação base dele é dendê quando cai } \\
\text { dentro do rio, alguém joga mandioca, esse tipo de } \\
\text { coisa ele gosta muito, agora principalmente o dendê } \\
\text { e milho verde.” E-3 } \\
\text { "É fezes humana,(...), dendê, camarão } \\
\text { pequenininho, e minhoca (...)" E-5 } \\
\text { “(...) são frutas, resto de frutas e aquelas algas.” E- } \\
16\end{array}$ & Onívoro \\
\hline Tambaqui (Colossoma sp.) & "Raízes (...) minhoca, outros peixes.” E-22 & Onívoro \\
\hline Tilápia (Oreochromis niloticus) & $\begin{array}{l}\text { "É um peixe herbívoro, se alimenta de algas, limo, } \\
\text { a gente chama o limo (...)" E-3 } \\
\text { "Se alimenta de frutas. A tilápia é mais de grão de } \\
\text { frutas." E-6 }\end{array}$ & Onívoro \\
\hline
\end{tabular}




\begin{tabular}{|c|c|c|}
\hline & $\begin{array}{l}\text { “(...) a barriguinha tava cheio de camarão e o limo } \\
\text { do rio que elas se alimentava.” E-13 }\end{array}$ & \\
\hline $\begin{array}{l}\text { Traíra } \\
\text { (Hoplerythrinus unitaeniatus) }\end{array}$ & $\begin{array}{l}\text { "Ele se alimenta de tudo que se mexe na água, mas } \\
\text { basicamente o lambari, que é o que tem nesse rio, } \\
\text { os peixes menores, o acará, até a própria traíra. } \\
\text { Ele é um peixe predador, mas é canibal também, ele } \\
\text { pratica o canibalismo." E-3 } \\
\text { "É piaba, é minhoca..." E-5 }\end{array}$ & Carnívoro \\
\hline $\begin{array}{l}\text { Tucunaré } \\
\text { (Cichla } \mathrm{sp.)}\end{array}$ & $\begin{array}{l}\text { "Se alimentava de outros peixes pequenos, (...), já } \\
\text { achei piabas pequenas dentro do tucunaré." E-16 }\end{array}$ & Carnívoro \\
\hline
\end{tabular}

Através da literatura pode-se confirmar os relatos fornecidos pelos pescadores sobre a alimentação dos peixes. Na análise do conteúdo estomacal do Geophagus brasiliensis no reservatório de Capivari Abelha e Goulart (2004), identificaram uma vasta diversidade em recursos alimentares tanto de origem vegetal quanto animal. O mesmo foi registrado por Oliveira e Bennemann (2005) ao avaliar o material do estômago do acará e encontrar, como principal alimento, insetos e vegetais. Ainda neste trabalho, as autoras observaram o conteúdo estomacal do bobó (Poecilia reticulata), identificando a presença de insetos e outros itens diversos, o que corrobora as informações dos pescadores.

Utilizando o mesmo método, Casatti (2002), em estudo com peixes em um riacho na bacia do Alto rio Paraná, verificou no estômago de três diferentes espécies de acari (Hypostomus $\mathrm{sp}$ ) grande ocorrência de algas, sendo esta sua principal fonte nutricional. A autora também acompanhou o comportamento alimentar de piabas e registrou a prática desses peixes em coletar partículas dispersas na corrente d'água, contendo, dentre os itens alimentares, a presença de insetos.

Pompeu e Godinho (2003), durante estudos em comunidades de peixes de três lagoas marginais do médio São Francisco registraram os itens alimentares encontrados no estômago das diferentes espécies pesquisadas. Dentre estas, os autores identificaram que indivíduos do gênero Brycon (piabanha) se alimentaram em maior proporção de algas e que os peixes do gênero Cichla (tucunaré) tiveram a maior parte da sua dieta formada por peixes menores. Este último, também teve confirmado o seu hábito alimentar piscívoro por Gomes e Verani (2003), no reservatório de Três Marias.

Diversas espécies do gênero Leporinus (piau) foram estudadas em diferentes trabalhos e o conteúdo estomacal observado forneceu informações a respeito do hábito 
SILVA, T.A.; OLIVEIRA, W.D.S.; SAMPAIO, F.A.C. Etnoconhecimento de pescadores artesanais sobre a ictiofauna do Rio Jiquiriçá, Bahia. Ethnoscientia v.6 n. 1, 2021. DOI: 10.22276/ethnoscientia.v6i1.375

alimentar deste grupo. Tanto Durães et al., (2001), quanto Gomes e Verani (2003), identificaram a presença de algas, raízes, frutos e larvas de insetos no material analisado, caracterizando um hábito onívoro.

Durante estudos realizados nos rios São Francisco e Doce por Vieira et al., (2015), destacaram os hábitos alimentares de diferentes espécies de peixes. A exemplo do cambuti, do gênero Callichthys, os autores identificaram diversos itens, caracterizando sua dieta como onívora. No conteúdo estomacal do bagre (Rhamdia quelen) foram detectados invertebrados, peixes e material vegetal. Já em espécies dos gêneros Colossoma e Brycon e na Poecilia reticulata foram verificadas a presença de material vegetal e invertebrados. Nas tilápias (Oreochromis niloticus) foram observados organismos do sedimento e detritos orgânicos. Quanto à traíra (Hoplerythrinus unitaeniatus), Mérona e Rankin-de-Mérona (2004), identificaram peixes e insetos dentre as preferências alimentares em diferentes fases de vida.

Conforme os estudos citados, percebeu-se uma forte convergência entre as informações científicas com a dos pescadores. O conhecimento sobre a ictiofauna representa para esta comunidade um elemento de grande importância na subsistência e no aspecto cultural, entretanto, corre risco de ser extinto devido a baixa adesão dos jovens a atividade de pesca. Esta afirmação pode ser verificada no relato do pescador E.16: "Antigamente se dizia: -Cuidado com esse menino na beira do rio! Hoje o menino pode ir pro rio? Não! (...) Não tem rio. Não sabe nada de peixe!”

Castelli e Wilkinson (2002), consideram que a perda de conhecimento folk é tão séria quanto a da biodiversidade, pois as riquezas das informações que comunidades tradicionais possuem, além de caracterizar sua história, auxiliam na conservação ambiental.

\subsection{Etnoconhecimento sobre a distribuição espacial dos peixes}

A interação entre diferentes espécies de peixes em um ambiente que fornece variações ao longo da sua extensão, faz com que cada grupo de indivíduos busque locais específicos, no qual encontram as melhores condições para sua sobrevivência. Através das entrevistas, os pescadores demonstraram conhecer os ambientes em que as variedades de peixes estão distribuídas, como visto no Quadro 3.

A observação em detalhes do local, permite que haja uma caracterização do ambiente e mapeamento dos principais espaços de ocorrências das espécies. A atenção à preferência ambiental dos peixes permitiu ao pescador organizar seu instrumento de pesca 
SILVA, T.A.; OLIVEIRA, W.D.S.; SAMPAIO, F.A.C. Etnoconhecimento de pescadores artesanais sobre a ictiofauna do Rio Jiquiriçá, Bahia. Ethnoscientia v.6 n. 1, 2021. DOI: 10.22276/ethnoscientia.v6i1.375

de acordo com o objetivo da sua captura. Observou-se também que esse conhecimento é repassado aos descendentes dos pescadores, conferindo benefícios na pesca de subsistência, aumentando a eficiência nas capturas dos peixes, por exemplo.

Quadro 3. Informações sobre distribuição espacial dos peixes, fornecidas pelos pescadores do rio Jiquiriçá, Bahia.

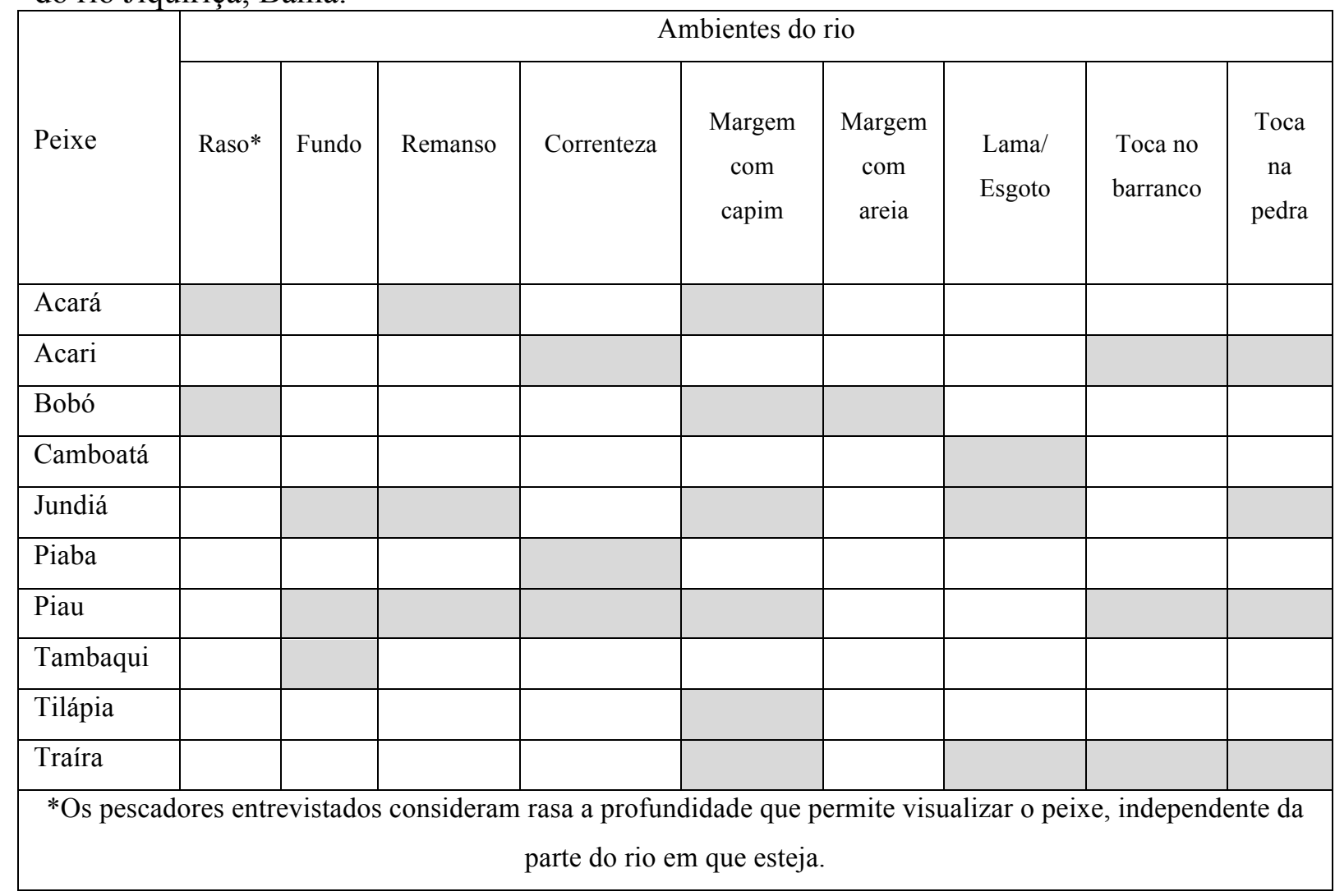

Muito desse conhecimento dos pescadores sobre a ocorrência no ambiente e a distribuição espacial dos peixes, construída pela observação ou transmissão oral pode ser confirmado na literatura. As descrições são similares para as espécies do gênero Leporinus (piau), quanto a ocorrência deste peixe tanto em partes fundas do leito, quanto nas margens, em meio a vegetação, além de também ser capturado em trechos com correntezas e/ou com fundo rochoso (VIEIRA e BIRINDELLI, 2005).

Para o bagre jundiá (Rhamdia quelen), Casatti (2002) registrou seu comportamento habitando preferencialmente as áreas do fundo dos rios bem como a presença de diferentes espécies de acaris (Hypostomus) em meio às pedras submersas. Espécimes deste último gênero também foram observadas por Buckup et al. (2014) em áreas de substrato arenoso ou argiloso, com correnteza rápida a moderada. Estes autores registraram também o jundiá 
SILVA, T.A.; OLIVEIRA, W.D.S.; SAMPAIO, F.A.C. Etnoconhecimento de pescadores artesanais sobre a ictiofauna do Rio Jiquiriçá, Bahia. Ethnoscientia v.6 n. 1, 2021. DOI: 10.22276/ethnoscientia.v6i1.375

(Rhamdia quelen) junto à vegetação e acarás (Geophagus brasiliensis) em áreas de águas sem muito movimento (remanso).

Sabino e Castro (1990), observaram no rio Indaiá, espécimes de G. brasiliensis nadando a meia-água (raso) dos remansos, durante o dia e no período noturno, estes mantinham-se parados, submersos em meio à vegetação marginal. Esta espécie de peixe também foi identificada por Malabarba et al (2013), habitando ambientes de águas calmas na Reserva Biológica do Lami José Lutzenberger. Neste mesmo local, os pesquisadores encontraram exemplares de Callichthys sp. que se mantinham em áreas de fundo lodoso.

Registros sobre Hoplerythrinus unitaeniatus confirmam a observação feita pelos pescadores, principalmente relacionada ao hábito deste peixe frequentar locais contendo lama. "Você encontra a traíra mais em área de lama" (E.22). Sobre esta habilidade da espécie, tanto Nelson (1984) quanto Polez et al. (2003), descrevem que a H. unitaeniatus consegue se desenvolver em ambientes lênticos.

Durante a caraterização da ictiofauna do riacho Quilombo, Thomé et al (2019) deparou-se com exemplares de $P$. reticulata e $R$. quelen. A primeira espécie foi encontrada na lâmina d'água (raso) e zona marginal, já a segunda demonstrou preferência por áreas do fundo e tocas, sendo considerada pelos autores como especuladora de substrato.

Em estudos realizados com as piabas do gênero Astyanax nos riachos da bacia do rio Guiraí, Súarez e Lima-Junior (2009) observaram sua preferência por ambientes de correnteza leve, ao passo que o jundiá foi encontrado em maior abundância em águas calmas (remanso).

\subsection{Petrechos da pesca artesanal}

Os pescadores artesanais da região estudada utilizam diversos métodos e petrechos para a captura dos peixes. Durante as entrevistas foi possível observar que existia uma divisão de local e forma de pesca entre homens e mulheres. Em sua maioria, as pescadoras atuavam no raso e nas margens com areia ou capim, utilizando geralmente o "balaio", "cesto" ou "monzoá", enquanto os homens pescavam no fundo, em locais com correnteza ou não e nas "tocas", utilizando diversas estratégias, como "vara de bambu com anzol”, "de mão", "tarrafa", "três-maio", "bomba" e "jiqui". Em algumas comunidades pesqueiras existem uma delimitação do ambiente de atuação do homem e da mulher, isso se dá por relações sociais e cultura local, sendo que as mulheres, geralmente, são direcionadas a 
SILVA, T.A.; OLIVEIRA, W.D.S.; SAMPAIO, F.A.C. Etnoconhecimento de pescadores artesanais sobre a ictiofauna do Rio Jiquiriçá, Bahia. Ethnoscientia v.6 n. 1, 2021. DOI: 10.22276/ethnoscientia.v6i1.375

formas de pesca mais ligadas às margens, devido a sua dupla jornada de trabalho-pesca e cuidados com o lar (WOORTMANN, 1991; MARTINS e ALVIM, 2016).

Grande parte dos mesmos métodos de pesca citados neste trabalho foram registrados por Gomes et al (2015) em pesquisa com pescadores artesanais do povoado da Cachoeirinha, município de Jequié, BA, que atuavam no rio das Contas. Costumes concordantes em comunidades de pescadores distintas, demonstram como estas práticas culturais ultrapassam limites geográficos sendo ajustadas com base nos recursos locais.

Dentre as formas de pesca, o uso de "bomba" ou dinamite, foi reconhecida pelos próprios pescadores como aquela que contribuiu com a grande diminuição de espécies de peixes no rio Jiquiriçá. Esta afirmação pode ser verificada na declaração de E.22 “(...) veio algumas pessoas jogando bomba, foi o que começou a destruir bastante os peixe, como aqui mesmo tinha muitas pessoas que jogavam bomba". Esta prática, também realizada no rio Vermelho nos séculos XIX e XX, foi noticiada por jornais da época como um dos grandes fatores de diminuição de peixes no local (VITAL e TEJERINA-GARRO, 2018).

De acordo com as entrevistas, em épocas de cheia, acontecia a construção de "paripes". A pescadora E.15 define essa estrutura de pesca como uma "construção feita com madeira dentro do rio (...) como se fosse uma estipa (...), de um lado ficava mais perto da margem pra poder ficar entrando, se deslocando. Ele ficava assim inclinado e aí então (...) os peixes vem por aqui, cai e não tem como voltar mais”. Neste período havia uma cooperação entre homens e mulheres pela grande quantidade de peixes coletados, “(...) quando a água vinha trazendo os peixes a água caia embaixo, porque era de tira, e os peixes ficavam ali pulando. Aí os homens pegava e ia jogano pras mulheres colocar no cesto" (E.14).

\subsection{Etnoconhecimento dos pescadores sobre as espécies não-nativas}

Durante as entrevistas os pescadores demonstraram conhecer espécies não-nativas, introduzidas ou exóticas no rio ao citar a pescada branca, carpa, tambaqui, tucunaré, bagre, tilápia e o curimbatá como indivíduos introduzidos ao ambiente. Entretanto a pescada branca, carpa, tambaqui e o tucunaré foram citados por um número pequeno de participantes $(9 \%)$, curimbatá $(26 \%)$ e o bagre $(4 \%)$, isto porque seu aparecimento aconteceu em regiões específicas, demonstrando que a introdução destes peixes afetou apenas determinadas localidades do rio. 
A tilápia foi mencionada por um número maior de pescadores (91\%), devido esta ter alcançado alto povoamento do ambiente no qual foi introduzida. É importante destacar que a tilápia só foi reconhecida como não-nativa por pescadores que possuíam mais de 35 anos de experiência na pesca e que eram filhos de pescadores, declarando que esta informação foi passada pelos pais. A introdução de novas espécies em ambientes naturais é um tipo de interferência antrópica que altera a composição da ictiofauna e pode modificar a densidade de algumas populações (MOURA e MARQUES, 2007). Isto demonstrou como a construção da memória ambiental pode ser perdida com o passar dos anos, sendo modificada pela mais recente conjuntura percebida pela população que ali habita no momento, fazendo com que espécies nativas sejam substituídas na memória dos pescadores, devido a introdução de espécies exóticas.

Outra espécie exótica também presente no rio Jiquiriçá e que não foi relatada nem nas entrevistas com os pescadores neste estudo e nem nos estudos de Burger e colaboradores (2011) é o bagre-africano (Clarias gariepinus). Esta espécie foi apontada por um proprietário rural como a responsável pelo desaparecimento de crustáceos como o pitú e camarão-cavalo, além de outras espécies de peixes.

As percepções dos entrevistados sobre mudanças ambientais ocasionadas por ações antrópicas ocorridas na região têm como fatores as espécies exóticas, juntamente com o assoreamento, construção de barragens, destruição dos afluentes e a agricultura foram mencionados num mesmo patamar pelos informantes. Apesar das espécies não-nativas diminuírem a qualidade e a quantidade do pescado (AGOSTINHO et al., 2007), poucos pescadores locais associaram a redução da pesca à introdução de espécies. Os impactos desta ação na pesca e nos recursos naturais é mais perceptível para os pescadores com mais de 20 anos na atividade. Entretanto, os pescadores mais jovens parecem ter assimilado naturalmente as espécies exóticas como nativas. Independentemente dos motivos, todos os participantes identificaram uma forte diminuição dos recursos pesqueiros da região. Esta mesma detecção foi relatada por pescadores do reservatório de Furnas, durante o estudo etnoictiológico realizado por Azevedo-Santos et al., (2010).

Além deste, outros impactos também foram indicados pelos pescadores, que de uma forma conjunta tem acarretado a diminuição da pesca. Dentre os 23 entrevistados, apenas sete ainda continuam pescando no rio Jiquiriçá. Dos outros 16 pescadores, cinco continuam desenvolvendo atividade pesqueira em outro local e 11 abandonaram definitivamente a prática. Para 56,3\% dos pescadores entrevistados que deixaram de pescar no rio Jiquiriçá, os principais motivos foram a degradação do rio e o alto índice de contaminação pelo 
SILVA, T.A.; OLIVEIRA, W.D.S.; SAMPAIO, F.A.C. Etnoconhecimento de pescadores artesanais sobre a ictiofauna do Rio Jiquiriçá, Bahia. Ethnoscientia v.6 n. 1, 2021. DOI: 10.22276/ethnoscientia.v6i1.375

parasita Schistosoma mansoni, causador da esquistossomose. Este último também foi registrado como um dos principais motivos que fizeram com que pescadores do povoado da Cachoeirinha deixassem de atuar no rio das Contas (GOMES et al., 2015). Segundo Nascimento e Meirelles (2020), a bacia do rio Jiquiriçá encontra-se entre aquelas que possuem prevalência excessiva do parasita Schistosoma mansoni no estado da Bahia.

Rodrigues (2008), em análise da água do rio Jiquiriçá no município de Ubaíra, constatou o alto índice de coliformes fecais presentes nas amostras, em virtude do lançamento de esgoto doméstico "in natura" diretamente no rio. Além disso, nos mesmos pontos foi registrado pelo autor a baixa saturação de oxigênio na água, o que compromete a vida de muitos indivíduos aquáticos. Assim, devido ao grau de degradação que se encontra o rio Jiquiriçá no trecho em estudo, a maioria dos entrevistados deixaram de desenvolver a atividade de pesca no local, se afastando do seu ambiente de identidade.

\section{CONCLUSÃO}

Os pescadores demonstraram possuir conhecimentos de grande importância, decorrentes da interação com o ambiente em que vivem e por meio da experiência adquirida de gerações antecessoras.

Com os resultados obtidos foi possível identificar a imediata necessidade de desenvolver medidas de recuperação e conservação do rio, visando garantir que esta tradicional atividade pesqueira possa ser mantida, assegurando tanto a manutenção do aspecto cultural e de subsistência da população quanto o ambiental.

\section{AGRADECIMENTOS}

Agradecemos aos pescadores e pescadoras por confiar e compartilhar seus saberes conosco. Agradecemos ao Comitê de Ética em Pesquisa da UESB, ao Instituto Federal Baiano, Campus Santa Inês, e a Fabiane Barreto, pelo auxílio na elaboração do mapa e aos revisores pelas contribuições no manuscrito. 
SILVA, T.A.; OLIVEIRA, W.D.S.; SAMPAIO, F.A.C. Etnoconhecimento de pescadores artesanais sobre a ictiofauna do Rio Jiquiriçá, Bahia. Ethnoscientia v.6 n. 1, 2021. DOI: 10.22276/ethnoscientia.v6i1.375

\section{REFERÊNCIAS BIBLIOGRÁFICAS}

ABELHA, M. C. F.; GOULART, E. Oportunismo trófico de Geophagus brasiliensis (Quoy \& Gaimard, 1824) (Osteichthyes, Cichlidae) no reservatório de Capivari, Estado do Paraná, Brasil. Acta Scientiarum Biological Sciences. Maringá, v. 26, n. 1, p. 37-45, 2004.

Agostinho, A.A.; GOMES, L. C.; PELICICE, F. M. Ecologia e manejo de recursos pesqueiros em reservatórios do Brasil. Maringá: Eduem, 2007. 501p.

AZEVEDO-SANTOS, V. M. et al. Concepções dos pescadores artesanais que utilizam o reservatório de Furnas, estado de Minas Gerais, acerca dos recursos pesqueiros: um estudo etnoecológico. Biotemas, Florianópolis, v. 23, n. 4, p. 135-145, 2010. http://dx.doi.org/doi: 10.5007/2175-7925.2010v23n4p135. Acesso em 15 mai. 2019.

BATISTA, M. A. N. Estudo de caso: Jiquiriçá - gestão participativa dos recursos hídricos da bacia do rio Jiquiriçá. Rio de Janeiro: IBAM/CAIXA, 2003. 82 p.

BENTO, D. M.; BEMVENUTI, M. A. Os peixes de água doce da pesca artesanal no sul da Lagoa dos Patos, RS: subsídios ao ensino escolar. Caderno de Ecologia Aquática. v. 3, n. 2, p. 33-41, 2008.

BIERNACKI, P.; WALDORF, D. Snowball sampling: problems and techniques of chain referral sampling. Sociological Methods and Research, v. 10, n. 2, p. 141-163, 1981.

BUCKUP, P. A.; BRITTO, M.R.; SOUZA-LIMA, R.; PASCOLI, J. Guia de identificação das espécies de peixes da bacia do rio das Pedras, município de Rio Claro, RJ. Rio de Janeiro: The Nature Conservancy, 2014. 79 p.

BURGER, R.; ZANATA, A.; CAMELIER, P. Estudo taxonômico da ictiofauna de água doce da bacia do Recôncavo Sul, Bahia, Brasil. Biota Neotropica, Campinas, v. 11, n. 4, p. 273-290, 2011. https://doi.org/10.1590/S1676-06032011000400024. Acesso em 16 abr. 2019.

CALDAS, J.; DIAS, J. H. P.; SHIBATTA, O. A. 40 peixes do Brasil: CESP 40 anos. Rio de janeiro: Doiis, $1^{\circ}$ ed., 2006, 208p.

CASATTI, L. Alimentação dos peixes em um riacho do Parque Estadual Morro do Diabo, Bacia do Alto rio Paraná, sudeste do Brasil. Biota Neotropica, Campinas, v. 2, n. 2, p. 1-14, 2002. Disponível em: <http://dx.doi.org/10.1590/S1676$06032002000200012>$. Acessado em 19 abr. 2019.

CASTELLI, P. G.; WILKINSON, J. Conhecimento tradicional, inovação e direitos de proteção. Estudos Sociedade e Agricultura, Rio de Janeiro, v. 10, n. 2, p. 89-112, 2002. Disponível em: https://www.revistaesa.com/ojs/index.php/esa/article/view/221/217. Acessado em: 03 jan 2021. 
DURÃES, R.; POMPEU, P. dos S.; GODINHO, A.L. Alimentação de quatro espécies de Leporinus (Characiformes, Anostomidae) durante a formação de um reservatório no sudeste do Brasil. Iheringia, Série Zoologia, Porto Alegre, n. 90, p.183-191, 2001. Disponível em: http://dx.doi.org/10.1590/S0073-47212001000100019 Acessado em: 03 jan 2021.

FAO - FOOD AND AGRICULTURE ORGANIZATION OF THE UNITED NATIONS. The state of world fisheries and aquaculture 2018: meeting the sustainable development goals. Rome. 2018. 227p. Disponível em: http://www.fao.org/3/19540EN/i9540en.pdf. Acessado em: 30 jun. 2019.

FARIA, R. H. S.; MORAIS, M.; SORANNA, M. R. G. DE S.; SALlUM, W. B. Manual de criação de peixes em viveiro. Brasília: CODEVASF, 2014. 136p. Disponível em: https:/www.codevasf.gov.br/acesso-ainformacao/institucional/biblioteca-geraldorocha/publicacoes/arquivos/manualdecriaodepeixesemviveirosreimpresso.pdf Acessado em: 30 jun. 2019.

FONSECA, F. A. L. ITUASSÚ; D. R.; CAVERO, B. A. S.; BORDINHON, A. M. Cultivo de curimatã (Prochilodus spp). In: BALDISSEROTTO, B. GOMES, L. C. Espécies nativas para piscicultura no Brasil. 2. ed. Santa Maria: UFSM, 2013.

FROESE, R.; PAULY, D. Editors. 2019. FishBase. World Wide Web electronic publication. Disponível em: www.fishbase.org, version (12/2019). Acessado em: 01 mai. 2020.

GOMES, J. H. C.; VERANI, J. R. Alimentação de espécies de peixes do reservatório de Três Marias. In: GODINHO, H. P.; GODINHO, A. L. Águas, peixes e pescadores do São Francisco das Minas Gerais. Belo Horizonte: PUC Minas, 2003.

GOMES, T. M.; OLIVEIRA, I. S.; BOCCARDO, L.; JUCÁ-CHAGAS, R. Os peixes e a arte da pesca no rio das Contas: memórias de pescadores e pescadoras do povoado da Cachoeirinha, Jequié, Bahia, Brasil. In: MONROY, R.; FLORES, A. G.; MORENO, J. M. P.; COSTA NETO, E. M. Saberes etnozoológicos Latinoamericanos. UEFS, Feira de Santana, 2015.

GRAÇA, W. J.; PAVANELLI, C. S. Peixes da planície de inundação do alto rio Paraná e áreas adjacentes. Eduem, Maringá, 2007.

IBGE. Instituto Brasileiro de Geografia e Estatística. O Brasil em síntese. 2019. Disponível em: https:/cidades.ibge.gov.br/brasil/ba/ubaira/historico. Acessado em: 01 de jul. de 2019.

KUBITZA, F. A evolução da tilapicultura no Brasil: produção e mercado. Panorama da Aquicultura, Rio de Janeiro, v. 13, n. 76, p. 25-35, 2003.

LORO, V. L. Aspectos da biologia, reprodução e manejo de Hoplias malabaricus e Hoplias lacerdae. In: BALDISSEROTTO, B.; GOMES, L. C. Espécies nativas para piscicultura no Brasil. 2. ed. Santa Maria: UFSM, 2013. 
SILVA, T.A.; OLIVEIRA, W.D.S.; SAMPAIO, F.A.C. Etnoconhecimento de pescadores artesanais sobre a ictiofauna do Rio Jiquiriçá, Bahia. Ethnoscientia v.6 n. 1, 2021. DOI: 10.22276/ethnoscientia.v6i1.375

MARQUES, J. G. W. Aspectos ecológicos na etnoictiologia dos pescadores do complexo estuarino-lagunar Mundaú-Manguaba, Alagoas. 1991. Tese. (Doutorado) Universidade Estadual de Campinas.

MARQUES, J. G. W. Etnoictiologia: pescando pescadores nas águas da transdisciplinaridade. Revista Ouricuri, Paulo Afonso, v. 2, n. 2, p. 9-36, 2012.

MARQUES, J. G. W. Pescando pescadores: ciência e etnociência em uma perspectiva ecológica, 2. ed. São Paulo. Núcleo de Apoio a Pesquisa sobre Populações Humanas e Áreas Úmidas Brasileiras, USP, 2001.

MARTINS, M. L. S.; ALVIM, R.G. Perspectivas do trabalho feminino na pesca artesanal: particularidades da comunidade Ilha do Beto, Sergipe, Brasil. Boletim do Museu Paraense Emílio Goeldi. Ciências Humanas, Belém, v. 11, n. 2, p. 379-390, 2016.

MALABARBA, L. R.; FIALHO, C. B.; BERTACO, V. A. CARVALHO, F. R.; DUFECH, A. P. S.; FERRER, J.; GIORA, J. Peixes. In: WITT, P.B.R. Fauna e flora da reserva biológica do Lami José Lutzenberger. Porto Alegre. Secretaria Municipal do Meio Ambiente, 2013.

MEIRELES, W. A. Piscicultor. 1. ed. Montes Claros: Setec/MEC, 2015.

MEDEIROS, P. M.; ALMEIDA, A. L. S.; LUCENA, R. F. P. Uso de estímulos visuais na pesquisa etnobiológica. In: ALBUQUERQUE, U. P.; LUCENA, R. F. P.; CUNHA, L. V. F. C. Métodos e técnicas na pesquisa etnobiológica e etnoecológica. Recife: Nupeea, 2010.

MÉRONA, B.; RANKIN-DE-MÉRONA, J. Food resource partitioning in a fish community of the central Amazon floodplain. Neotropical Ichthyology, Maringá, v.2, n.2, p.75-84, 2004 .

McBAY, L.G. The biology of the Tilapia nilotica Linnaeus. Proceedings of Annual Conference Southeastern Association of Game and fish Commissioners. Montgomery, v.1, n.1, p. 1-13, 1961.

MOURA, F. B. P., MARQUES, J. G. W. Conhecimento de pescadores tradicionais sobre a dinâmica espaço-temporal de recursos naturais na Chapada Diamantina, Bahia. Biota Neotropica, Campinas, v.7, n.3, p.119-126, 2007. Disponível em: https://doi.org/10.1590/S1676-06032007000300014. Acessado em: 22 jun. 2019.

MOURA, F. B. P., MARQUES, J. G. W. O povo dos Marimbus: etnoecologia de pescadores tradicionais na APA Marimbus-Iraquara. In: FUNCH, L. S. et al Serra do Sincorá: Parque Nacional da Chapada Diamantina. Feira de Santana: Randami, 2008.

MOURÃO, J. S.; NORDI, N. Comparações entre as taxonomias folk e científica para peixes do estuário do rio Mamanguape, Paraíba-Brasil. Interciência, Caracas, v. 27, n. 12, p. 664-668, 2002.

NASCIMENTO, I. M. E.; MEIRELLES, L. M. A. Análise do perfil epidemiológico 
SILVA, T.A.; OLIVEIRA, W.D.S.; SAMPAIO, F.A.C. Etnoconhecimento de pescadores artesanais sobre a ictiofauna do Rio Jiquiriçá, Bahia. Ethnoscientia v.6 n. 1, 2021. DOI: 10.22276/ethnoscientia.v6i1.375

da esquistossomose no Nordeste do Brasil. Research, Society and Development, v. 9, n. 11, p. 1-19, 2020.

NELSON, J. S. Fishes of the World. London: Wiley Interscience Publication John and Sons, 1984.

OLIVEIRA, D. C. BENNEMANN, S. T. Ictiofauna, recursos alimentares e relações com as interferências antrópicas em um riacho urbano no sul do Brasil. Biota Neotropica, Campinas, v.5, n.1, p. 95-107, 2005. Disponível em http://dx.doi.org/10.1590/S1676-06032005000100011. Acessado em: 15 abr. 2019.

OLIVEIRA, E. G.; SANTOS, F. J. de S.; PEREIRA, A. M. L.; LIMA, C. B. Produção de tilápia: mercado, espécie, biologia e recria. Circular Técnica 45. Teresina: Embrapa Meio-Norte, 2007. 12p

POLEZ, V.L.P.; MORAES, G.; SANTOS-NETO, C. Different biochemical strategies of two Neotropical fish to cope with the impairment of nitrogen excretion during air exposure. Brazilian Journal of Medical and Biological Research, v. 36, p. 279-285, 2003.

POMPEU, P. S.; GODINHO, H. P. Dieta e estrutura trófica das comunidades de peixes de três lagoas marginais do Médio São Francisco. In: GODINHO, H. P.; GODINHO, A. L. Águas, peixes e pescadores do São Francisco das Minas Gerais. Belo Horizonte: PUC Minas, 2003.

PORTO-FORESTI, F. CASTILHO-ALMEIDA, R. B.; SENHORINI, J. A.; FORESTI, F. Biologia e criação do lambari-do-rabo-amarelo (Astyanax altiparanae). In: BALDISSEROTTO, B.; GOMES, L. C. Espécies nativas para piscicultura no Brasil. 2. ed. Santa Maria: UFSM, 2013.

RAMIRES, M.; MOLINA, S. M. G.; HANAZAKI, N. Etnoecologia caiçara: o conhecimento dos pescadores artesanais sobre aspectos ecológicos da pesca. Biotemas, Florianópolis, v. 20, n.1, p.101-113, 2007.

RODRIGUES, M. A. R. Avaliação da qualidade da água do rio Jiquiriçá a jusante da cidade de Ubaíra-Bahia-Brasil através de variáveis físicas, químicas e biológicas. 2008. Dissertação. (Mestrado) Universidade Estadual de Santa Cruz.

ROZARIO, E. M.; TEIXEIRA, C. C.; SILVA, E. D.; TEIXEIRA, M. C. A relação homem-natureza nas comunidades tradicionais da ilha de Guriri-ES: subsídios à educação ambiental. 1. ed. Curitiba: Appris, 2018. 173p.

SABINO, J.; CASTRO, R. M. C. Alimentação, período de atividade e distribuição espacial dos peixes de um riacho da Floresta Atlântica (sudeste do Brasil). Revista Brasileira de Biologia, Rio de Janeiro, v. 50, n. 1, p. 23-36, 1990. Disponível em: https:/www.researchgate.net/publication/307914802_ALIMENTACAO_PERIODO DE_ATIVIDADE_E_DISTRIBUICAO_ESPACIAL_DOS_PEIXES_DE_UM_RIAC HO_DA_FLORESTA_ATLANTICA_SUDESTE_DO_BRASIL. Acessado em: 03 jan. 2021. 
SANT'ANNA, E. B. Condição e dieta de Hoplias malabaricus (bloch, 1794) em rios de águas branca e preta na bacia do rio Itanhaém, Itanhaém/SP. 2006. 105fls. Dissertação (Mestrado em Zoologia) - Instituto de Biociências da Universidade Estadual Paulista, Rio Claro, SP, 2006.

SANTOS, K. P. P.; VIEIRA, I. R.; ALENCAR, N. L.; SOARES, R. R.; BARROS, R. F. M. Fishing practices and ethnoichthyological knowledge in the fishing community of Miguel Alves, Piauí, Brazil. Boletim do Instituto de Pesca, v. 44, n. 1, p. 25-34, 2018 .

SARMENTO-SOARES, L. M.; MAZZONI, R.; MARTINS-PINHEIRO, R. F. A fauna de peixes na bacia do Rio Jucuruçu, leste de Minas Gerais e extremo Sul da Bahia. Pan-American Journal of Aquatic Sciences. v.4, n. 2, p. 193-207. 2009.

SATO, Y.; BAZZOLI, N.; RIZZO, E.; BOSCHI, M. B.; MIRANDA, M. O. T. Impacto a jusante do reservatório de Três Marias sobre a reprodução do peixe reofílico curimatá-pacu (Prochilodus argenteus). In: GODINHO, H. P.; GODINHO, A. L. Águas, peixes e pescadores do São Francisco das Minas Gerais. Belo Horizonte: PUC Minas, p. 327-345, 2003.

SCHULTER, E. P.; VIEIRA FILHO, J. E. R. Evolução da piscicultura no Brasil: diagnóstico e desenvolvimento da cadeia produtiva de tilápia. Brasília: IPEA, 2017.

SEI. Superintendência de Estudos Econômicos e Sociais da Bahia. Informações municipais. 2019.2 Disponível em: http://www.sei.ba.gov.br/index.php?option=com_wrapper\&view=wrapper\&Itemid=2 66. Acessado em: 01 de jul. de 2019.

SILVA FILHO, J. J.; NASCIMENTO, W. S.; ARAÚJO, A. S.; BARROS, N. H. C.; CHELLAPPA, S. Reprodução do peixe piau preto Leporinus piau (Fowler, 1941) e as variáveis ambientais do açude Marechal Dutra, Rio Grande do Norte. Biota Amazônia, Macapá, v. 2, n. 1, p. 10-21, 2012.

SILVA, I. H. Caracterização da reprodução e ensaios de crescimento da Tilápia Moçambicana (Oreochromis mossambicus, Peters 1852). $2015.105 \mathrm{fls}$. Dissertação (Mestrado em Aquacultura) - Escola Superior de Turismo e Tecnologia do Mar/Instituto Politécnico de Leiria, Peniche, 2015.

SILVA, J. T.; BRAGA, T. M. P. Etnoictiologia de pescadores artesanais da comunidade Surucuá (reserva extrativista Tapajós-Arapiuns). Amazônica Revista de Antropologia, Belém, v. 9, n. 1, p. 238-257, 2017.

SÚAREZ, Y. R.; LIMA-JUNIOR, S. E. Variação espacial e temporal nas assembléias de peixes de riachos na bacia do rio Guiraí, Alto Rio Paraná. Biota Neotropica, Campinas, v. 9, n. 1, p. 101-111, 2009.

THÉ, A. P. G.; MADI, E.F; NORDI, N. Conhecimento local, regras informais e uso do peixe na pesca do alto-médio São Francisco. In: GODINHO, H. P.; GODINHO, A. L. Águas, peixes e pescadores do São Francisco das Minas Gerais. Belo Horizonte: PUC Minas, p. 389-406, 2003. 
THOMÉ, M. P. M.; DE PAUlA, L. F. P.; ROSA, J. L. M.; SAROBA, C. C. Caracterização da ictiofauna de um riacho de Mata Atlântica, no âmbito de uma central geradora de energia, Carmo-RJ, Brasil. Revista Interdisciplinar do Pensamento Científico, Rio de Janeiro, v. 5, n. 5, p. 804-819, 2019. Disponível em: http://dx.doi.org/10.20951/2446-6778/v5n5a61. Acessado em: 03 jan. 2021.

TOLEDO, V. M.; BARRERA-BASSOLS, N. A etnoecologia: uma ciência pósnormal que estuda as sabedorias tradicionais. In: SILVA, V. A. et al. Etnobiologia e etnoecologia: pessoas e natureza na América Latina. 1. ed. Recife: NUPEEA, 2010 .

VASCONCELlOS, M. G. Atributos reprodutivos de peixes da bacia do rio São Francisco e implicações filogenéticas. 2007. 157fls. Tese (Doutorado em Ecologia e Recursos Naturais) - Universidade Federal de São Carlos, São Carlos, 2007.

VIEIRA, F.; BIRINDELLI, J. L. Leporinus thayeri Borodin, 1929. In: ROSA, R.; LIMA, F. Livro vermelho da fauna brasileira ameaçada de extinção: peixes. Brasília: ICMBIO, 2005.

VIEIRA, F.; GASPARINI, J. L.; MACIEIRA, R. M. Guia ilustrado dos peixes da bacia do rio Benevides - ES. Vitória: ACQUA Consultoria e Recuperação de Ambientes Aquáticos Ltda/São Joaquim Energia S.A., 2014. 100p.

VIEIRA, F.; GOMES, J. P.C.; MAIA, B.P.; SILVA, L. G.M. Peixes do Quadrilátero Ferrífero: guia de identificação. Belo Horizonte: Fundação Biodiversitas, 2015. $208 p$.

VITAL, A. V.; TEJERINA-GARRO, F. L. O incentivo à pesca comercial de Arapaima gigas (pirarucu) do rio Araguaia (Brasil central) na revista "A Informação Goyana" (1917-1935). Boletim do Museu Paraense Emílio Goeldi. Ciências Humanas, Belém v. 13, n. 1, p. 159-174, 2018.

ZAVALA-CAMIN, L. A. Introdução aos estudos sobre alimentação natural em peixes. Maringá: EDUEM, 1996.

ZEINEDDINE, G. C.; OLIVEIRA, K.S.; RAMIRES, M; BARRELLA, W.; GUIMARÃES, J.P. Percepções dos pescadores artesanais e a pesca acidental de tartarugas marinhas na reserva de desenvolvimento sustentável Barra do Una, Peruíbe, São Paulo, Brasil. Ethnoscientia, Botucatu, v. 3, p. 1-13, 2018.

WOORTMAN, E. F. Da complementaridade à dependência: a mulher e o ambiente em comunidades pesqueiras do Nordeste. Série Antropologia 111. Brasília: Universidade de Brasília, Departamento de Antropologia, 1991. 